\title{
The importance of herbal medicine use in the German health-care system: prevalence, usage pattern, and influencing factors
}

\author{
Alexandra N. Welz, Agnes Emberger-Klein and Klaus Menrad ${ }^{*}$
}

\begin{abstract}
Background: Prevalence rates for herbal medicine (HM) have been increasing worldwide. However, little is known about prevalence, user characteristics, usage pattern and factors influencing HM usage for the general German population.

Methods: A nationwide online survey on HM usage was conducted in Germany. The 2906 participants were categorised into three groups: the ones who used HM in the last 12 months, the ones who did not use HM in the last 12 months but in their lifetime, and the ones who did not use HM until now. Data were analysed by descriptive statistics, Chi Square tests and binary hierarchical logistic regression analyses.

Results: Prevalence rates of HM were found to be very high for the general German population. Self-medication appeared as a common praxis, when at the same time HM users responded that they do not inform their physician about it, rate their knowledge about HM as somewhat poor, and use the internet as the most frequent source of information. The HM user in the last 12 months was found to include people that were more likely female, highly educated, privately insured, employed, and engaged in a more health-oriented lifestyle. While certain sociodemographicand health-related variables influence HM usage vs. non-usage, they explain variance only to a limited extent. For distinguishing the user in the last 12 months vs. the less recent user who did not use HM in the last 12 months, ratings on different reasons for HM usage were found to perform better as predictors than sociodemographic- and healthrelated variables.

Conclusions: This study demonstrated that HM usage plays an essential role in the German health-care system. Furthermore, the HM usage pattern may be potentially harmful for patients, as it included self-medication, little knowledge on interaction- and side-effects of $\mathrm{HM}$, and a lack of communication with physicians about the usage. Moreover, prediction of HM usage in the previous year is impacted by variables beyond conventional sociodemographicand health-related ones. In view of the high prevalence rates of HM in Germany, medical as well as health service providers should be aware of these issues.
\end{abstract}

\section{Background}

Usage of complementary and alternative medicine (CAM) has been increasing worldwide during the past decades [1]. Herbal medicine (HM) was often found to be among the most popular and strongest growing forms of CAM, but as discussed in the literature HM prevalence rates show a broad variety $(6-48 \%)$ in $\mathrm{EU}$

\footnotetext{
* Correspondence: klaus.menrad@hswt.de

Technical University of Munich, TUM Campus Straubing for Biotechnology and Sustainability, Chair of Marketing and Management of Biogenic Resources, Weihenstephan-Triesdorf University of Applied Sciences, Petersgasse 18, 94315 Straubing, Germany
}

countries [2]. Three main reasons may explain this broad range of prevalence rates: First, country-specific variations including different cultural habits, legal details, and health insurance policies [2-5]. Second, samples that were used in previous studies often differed markedly in terms of whether or not the general population is considered, or if the sample is confined to specific subgroups such as pharmacy visitors, pregnant women, elderly people, cancer patients or people with chronic diseases [6-10]. Third, a somewhat unclear and nonuniform definition of HM was often used in the literature, e.g., HM was summarised with other "natural

(c) The Author(s). 2019 Open Access This article is distributed under the terms of the Creative Commons Attribution 4.0 International License (http://creativecommons.org/licenses/by/4.0/), which permits unrestricted use, distribution, and 
health products" [11] or dietary supplements such as mega-vitamins $[12,13]$. These three issues may at least in part explain the strong variations in HM prevalence rates, and as such could of course also influence results on user characteristics, use-related variables, and factors predicting HM usage. Therefore, as emphasized in a review paper by Eardley et al. [2], it would be important to examine the user and use-related behaviour per country and per CAM-treatment on the basis of a clear, welldefined terminology. While previous work reported HM specific results for several countries [11, 13-15], to the best of our knowledge data on HM user characteristics, use-related variables, and predictors of HM usage for the general population in Germany have not been reported recently. Such data would be interesting for Germany in particular, because HM prevalence for the general population rates soared from $\sim 50 \%$ in 1970 to $70 \%$ in 2010 [16], and were found to be very high compared to other countries $[14,15,17]$. Also, yearly reports of the German Medicines Manufacturers' Association showed steadily increasing turnover and sales volume figures for HM products in Germany $[18,19]$.

In this work, we undertook a nationwide online survey regarding $\mathrm{HM}$ usage in the general population in Germany. We report prevalence rates, comprehensive sociodemographic and health-related characteristics related to HM usage, and compare the various user types. Furthermore, we provide insights in users' aims and their pattern for HM usage, in addition to an examination of influencing factors for HM usage. Given that there is little population-based data in Germany and prevalence rates for HM are extremely high, our findings support the important task of establishing a better understanding of the role that HM plays in the German health-care system as well as the variables influencing the use of it. Such knowledge is critical for medicinal professionals, health-care providers as well as healthservice and health-policy decision makers.

\section{Method}

\section{Study design and data collection method}

HM was defined as all plant-derived products including their natural form, as well as pills derived from extracts. We considered the general population in a crosssectional study and not a specific illness group because guided by literature results we hypothesised that HM is not only used to treat an illness, but also to promote health or for preventive measures [20, 21]. In order to provide a representative picture of the general German population (18+), quota sampling was used to ensure that the sociodemographic characteristics of the participants reflected the statistical distributions of gender, age, federal state, size of household and residence in Germany. We performed an online survey using a standardised questionnaire (see below for more details) in January and February 2018 in Germany, which was the timeframe required to fulfil the requested quotas. The survey was conducted via an online panel of a market research institute, who recruited all participants. The criteria for participating in the survey were being at least 18 years old and German speaking. Before starting the questionnaire, the participants were informed about the purpose of the study and its privacy policy, and gave their consent. Participation was voluntary and monetarily compensated via the market research institute.

The online survey was completed by 3394 individuals. We carefully screened the data to ensure a valid and reliable dataset, following the criteria for data clearing provided by Schendera [22]. The remaining sample included 2906 participants. We note that this study was approved by the Ethics Commission of the Faculty of Medicine, Technical University of Munich on 08th January 2018.

\section{Questionnaire design}

For the purpose of this survey, we developed a questionnaire (see Additional file 1) for which we mainly used established items and scales applied in previous studies, for example out of the survey instrument used for the $\mathrm{Na}$ tional Health Interview Survey (NHIS) in the US [23]. Some of the items were adapted to country-specific circumstances, for example the list of herbs available in Germany. Furthermore, we developed items based on the results of our recent qualitative study, such as the items addressing the reasons of usage and the sources of information [24]. The entire questionnaire was reviewed critically by all authors as well as two research assistants. Subsequently, an online pretest (results not included in the final dataset) was performed to review the timing, clarity and general understanding of the questionnaire. Through all these steps, the questionnaire has been updated and improved. This careful process was necessary to ensure a valid, reliable and credible measuring instrument.

\section{Questionnaire sections and items}

The first section of the questionnaire contained HM use-related questions: At the very beginning, in line with the procedure of the NHIS in the US [23], it was asked whether HM was ever used and - if yes - whether it was used in the last 12 months with the question: "Have you ever (question 1) respectively in the last 12 months (question 2) used natural herbs for your own health or treatment?" People who answered with "yes" received further questions regarding the following issues: aims of usage (treat illness, prevent illness, promote health), sources of information and trust in sources, selfperceived knowledge about HM (6 items on 5 point Likert scale ranging from very poor (1) to very good (5)), reasons for HM usage (13 items on 5 point Likert scale 
ranging from strongly disagree (1) to strongly agree (5)), whether or not participants use HM in self-medication, and whether or not they inform their physicians about the use. Furthermore, participants had to choose out of 23 possible indications for which they use HM and rate the perceived helpfulness (not at all, somewhat and a great deal). They also had to choose herbs they had used out of a list containing 26 herbs.

Section 2 addressed health-related questions, about the self-perceived health status (very poor, poor, fair, good, very good), chronic diseases (yes/no), as well as questions about physical activity (days per week), smoking (current, occasional, former, non), alcohol consumption, and whether or not specific preventive healthactivities (e.g. vaccination) were performed (yes/no).

Section 3 contained questions on sociodemographic information such as age, gender, marital status, education, occupation and health-insurance status of the participants.

\section{Statistical analysis}

Descriptive statistics such as frequencies, mean values and percentages were used for evaluating sample characteristics and analysing use-related variables such as HM indications or aims. To facilitate group comparisons, some categories of variables were merged, e.g. the subcategories of former smokers and non-smokers were merged into one category of non-smokers, and current and occasional smokers into one category of smokers.

For testing group differences between the HM user in the previous 12 months (1), the HM user who did not take HM in the previous 12 months (2), and the nonuser (3), Chi Square tests were performed and tested on the $p<0.05$ significance level. Furthermore, binary hierarchical logistic regression analyses were used for identifying, in model 1, the relevant predictors for being a 12month user (group 1) compared to a non-user (group 3) and, in model 2, for being a 12-month user (group 1) compared to being a less recent user (group 2). We decided that two separate regression models comparing two groups to each other, in a binary analysis, is more appropriate than an ordinal one because only for two out of the three groups could we enter "reasons for HM usage" as variables in the analysis. Consequently, due to the different number and sets of variables it was not possible to compare all three groups in one ordinal model.We applied a hierarchical model for analysing the incremental amount of variance that is explained when different sets of predictors (see below) are included successively in the model [25-27]. For both regression models, we used as the dependent variable "HM use in the last 12 months" (yes $=1 /$ no $=0$ ), excluding in model 1 the group of users who did not take HM in the previous 12 months (group 2) and in model 2 the group of non-users (group 3).
In both models, we entered as independent variables all sociodemographic variables (see Table 1) in a first block, and all health related variables (see Table 2) in a second block, which were found to be significant predictors in previous research on HM [15, 28-30]. We excluded the variable "marital status" to avoid collinearity, due to its high correlation with the variable "size of household". Additionally, in model 2 we entered in a third block variables of user ratings measuring reasons for HM usage. Because addressing the reasons for HM usage was of course only relevant for the groups of users $(1,2)$, these variables were only included in regression model 2. The results shown in Table 6 were those of the final hierarchical model, in which nominal scale variables were entered as $\mathrm{k}-1$ dummy variables. Note that the respective reference group is described in the table captions.

For all calculations, we used the statistics software package SPSS for Windows, release 23.

\section{Results}

In this section, we first report the status quo of the HM usage in the general German population in regard to sociodemographic and health-related characteristics and usage pattern. In the last part of the results section, we report results on influencing factors for HM usage.

\section{Prevalence, sociodemographic and health-related characteristics}

Table 1 shows the distribution of sociodemographic variables of the total sample as well as the comparison between the three groups. The sample included 2906 participants, of which 2192 people used HM in the previous 12 months (75.4\% 12 -month prevalence). 328 people did not use HM in the previous 12 months, but did so at earlier times (86.7\% lifetime prevalence) and 386 participants had never used HM. Interestingly, 92\% of the participants that had used HM in the previous year did so in self-medication, of which only $38 \%$ informed their physician. Results from Chi Square tests showed that HM users were mostly female, educated longer, employed and insured privately. Furthermore, statistically significant differences $(p<0.05)$ were found for the variables age and size of household. The variable marital status did not show differences between the groups.

The results for health-related variables are shown in Table 2. Results from Chi Square tests showed that recent HM users were more often suffering from a chronic disease, non-smokers, and performed physical activity more frequently, compared to the other groups. Statistically significant differences between the groups were also found in preventive health behaviour: recent HM users did more often annual dentist check-ups, preventive 
Table 1 Frequency table on sociodemographic characteristics of study participants and results of $x^{2}$ test

\begin{tabular}{|c|c|c|c|c|c|}
\hline & $\begin{array}{l}\text { Total sample, } \\
n=2906 \\
(\%)\end{array}$ & $\begin{array}{l}\text { HM user in previous } \\
\text { year }(1) \\
n=2192 \\
(\%)\end{array}$ & $\begin{array}{l}\text { HM user not in } \\
\text { previous year ( } 2 \text { ) } \\
n=328 \\
(\%)\end{array}$ & $\begin{array}{l}\text { HM non-user } \\
(3), \\
n=386 \\
(\%)\end{array}$ & $\begin{array}{l}x^{2}(\mathrm{df}), \\
p \text { value }\end{array}$ \\
\hline Total N & 100.0 & 75.4 & 11.3 & 13.3 & \\
\hline \multicolumn{6}{|l|}{ Gender } \\
\hline Male & 49.4 & 44.5 & 59.8 & 68.4 & \multirow{2}{*}{$\begin{array}{l}x^{2}(2)=90.62 \\
p=.000\end{array}$} \\
\hline Female & 50.6 & 55.5 & 40.2 & 31.6 & \\
\hline \multicolumn{6}{|l|}{ Years of Education } \\
\hline$<12$ Years & 50.1 & 47.4 & 54.9 & 60.9 & \multirow{2}{*}{$\begin{array}{l}x^{2}(2)=27.12 \\
p=.000\end{array}$} \\
\hline$\geq 12$ Years & 49.9 & 52.6 & 45.1 & 39.1 & \\
\hline \multicolumn{6}{|l|}{ Occupation } \\
\hline Employed & 64.7 & 66.0 & 60.1 & 61.4 & \multirow{2}{*}{$\begin{array}{l}x^{2}(2)=6.59 \\
p=.037\end{array}$} \\
\hline Unemployed & 35.3 & 34.0 & 39.9 & 38.6 & \\
\hline \multicolumn{6}{|l|}{ Health insurance } \\
\hline Public & 78.6 & 77.4 & 80.2 & 83.9 & \multirow{2}{*}{$\begin{array}{l}x^{2}(2)=9.65 \\
p=.047\end{array}$} \\
\hline Private & 21.4 & 22.6 & 19.8 & 16.1 & \\
\hline \multicolumn{6}{|l|}{ Age group (years) } \\
\hline $18-29$ & 16.2 & 17.6 & 13.7 & 10.6 & \multirow{5}{*}{$\begin{array}{l}x^{2}(8)=17.39, \\
p=.026\end{array}$} \\
\hline $30-39$ & 13.0 & 13.0 & 10.7 & 14.5 & \\
\hline $40-49$ & 17.2 & 17.0 & 18.0 & 17.9 & \\
\hline $50-59$ & 19.4 & 19.1 & 18.9 & 21.5 & \\
\hline$\geq 60$ & 34.2 & 33.3 & 38.7 & 35.5 & \\
\hline \multicolumn{6}{|l|}{ Size of household size } \\
\hline 1 & 25.2 & 23.0 & 30.8 & 32.9 & \multirow{4}{*}{$\begin{array}{l}x^{2}(6)=31.37 \\
p=.000\end{array}$} \\
\hline 2 & 42.8 & 42.8 & 42.1 & 43.3 & \\
\hline 3 & 15.7 & 16.7 & 13.7 & 11.7 & \\
\hline$\geq 4$ & 16.3 & 17.5 & 13.4 & 12.2 & \\
\hline \multicolumn{6}{|l|}{ Marital Status } \\
\hline Married/cohabitating & 51.8 & 53.0 & 47.3 & 49.0 & \multirow{4}{*}{$\begin{array}{l}x^{2}(6)=7.55 \\
p=.273\end{array}$} \\
\hline Divorced/separated & 14.3 & 13.7 & 17.7 & 14.5 & \\
\hline Single & 30.1 & 29.7 & 30.5 & 32.1 & \\
\hline Widowed & 3.8 & 3.6 & 4.6 & 4.4 & \\
\hline
\end{tabular}

medical check-ups, and were more likely to be currently vaccinated against tetanus. The variables of flu vaccination, alcohol consumption and self-perceived healthstatus did not show differences between the groups.

\section{Usage pattern}

For this part of the results section, we focus on the data for the participants who used HM in the previous year (group 1), in order to enable comparison of our findings to previous studies [12, 29]. Regarding the aims of HM usage, $93.1 \%$ of the participants used HM to treat current or chronic illnesses, $70.7 \%$ to promote health, and $60.9 \%$ to prevent illnesses. The most frequently used herbs were peppermint (58.4\%), camomile (58.3\%), sage
(55.7\%), ginger (51.9\%), eucalyptus (46.3\%), onion (33.2\%), valerian (33.1\%), stinging nettle (30.5\%), St. John's wort (30.3\%), Aloe vera (28.4\%), and arnica (28.4\%). The most frequent conditions for which HM were used were common cold/flu infection $(65.8 \%)$, respiratory problems $(61.8 \%)$, and gastrointestinal diseases (47.8\%). The perceived helpfulness of HM was greatest for insect bites, gastrointestinal and respiratory problems. Especially for tinnitus and depression, HM was not perceived as being very helpful. Frequencies of all indications for which HM was used and the reported helpfulness are shown in Table 3.

To the question "Where do you inform yourself about the effectiveness and possible areas of application of 
Table 2 Frequency table on health-related characteristics of study participants and results of $x^{2}$ test

\begin{tabular}{|c|c|c|c|c|c|}
\hline & $\begin{array}{l}\text { Total sample, } \\
n=2906 \\
(\%)\end{array}$ & $\begin{array}{l}\text { HM user in previous } \\
\text { year }(1) \\
n=2192 \\
(\%)\end{array}$ & $\begin{array}{l}\text { HM user not in } \\
\text { previous year (2) } \\
n=328 \\
(\%)\end{array}$ & $\begin{array}{l}\text { HM non-users } \\
(3)_{1} \\
n=386 \\
(\%)\end{array}$ & $\begin{array}{l}x^{2}(\mathrm{df}), \\
p \text { value }\end{array}$ \\
\hline \multicolumn{6}{|c|}{ Self-perceived health status } \\
\hline Very good, good & 62.8 & 63.0 & 63.4 & 61.4 & \multirow{2}{*}{$\begin{array}{l}x^{2}(2)=.41 \\
p=.813\end{array}$} \\
\hline Fair, poor, very poor & 37.2 & 37.0 & 36.6 & 38.6 & \\
\hline \multicolumn{6}{|l|}{ Chronic disease } \\
\hline Yes & 53.6 & 56.6 & 48.2 & 41.5 & \multirow{2}{*}{$\begin{array}{l}x^{2}(2)=35.57, \\
p=.000\end{array}$} \\
\hline No & 46.4 & 43.4 & 51.8 & 58.5 & \\
\hline \multicolumn{6}{|l|}{ Smoking Status } \\
\hline Current & 30.1 & 28.8 & 33.2 & 35.0 & \multirow{2}{*}{$\begin{array}{l}X^{2}(2)=7.55 \\
p=.023\end{array}$} \\
\hline Former, Never & 69.9 & 71.2 & 66.8 & 65.0 & \\
\hline \multicolumn{6}{|c|}{ Regular Alcohol Consumption } \\
\hline Yes & 64.0 & 64.5 & 63.4 & 61.7 & \multirow{2}{*}{$\begin{array}{l}x^{2}(2)=1.21 \\
p=.545\end{array}$} \\
\hline No & 36.0 & 35.5 & 36.6 & 38.3 & \\
\hline \multicolumn{6}{|c|}{ Physical Activities (d./week) } \\
\hline $0-2$ & 57.0 & 54.6 & 62.2 & 65.8 & \multirow{2}{*}{$\begin{array}{l}x^{2}(2)=20.93, \\
p=.000\end{array}$} \\
\hline $3-7$ & 43.0 & 45.4 & 38.8 & 34.2 & \\
\hline \multicolumn{6}{|l|}{ Flu vaccination } \\
\hline Yes & 22.2 & 22.6 & 22.6 & 19.7 & \multirow{2}{*}{$\begin{array}{l}x^{2}(2)=1.62 \\
p=.445\end{array}$} \\
\hline No & 77.8 & 77.4 & 77.4 & 80.3 & \\
\hline \multicolumn{6}{|l|}{ Annual dentist check-ups } \\
\hline Yes & 74.8 & 78.0 & 67.1 & 63.5 & \multirow{2}{*}{$\begin{array}{l}x^{2}(2)=48.33 \\
p=.000\end{array}$} \\
\hline No & 25.2 & 22.0 & 32.9 & 36.5 & \\
\hline \multicolumn{6}{|c|}{ Preventive medical check-ups } \\
\hline Yes & 53.7 & 56.6 & 47.9 & 42.0 & \multirow{2}{*}{$\begin{array}{l}x^{2}(2)=33.35 \\
p=.000\end{array}$} \\
\hline No & 46.3 & 43.4 & 52.1 & 58.0 & \\
\hline \multicolumn{6}{|c|}{ Current tetanus vaccination } \\
\hline Yes & 74.6 & 76.1 & 72.9 & 67.1 & \multirow{2}{*}{$\begin{array}{l}x^{2}(2)=14.72 \\
p=.001\end{array}$} \\
\hline No & 25.4 & 23.9 & 27.1 & 32.9 & \\
\hline
\end{tabular}

HM", researching on the internet was the most frequent answer, followed by consultation of pharmacists, parents and family members, and physicians (see Table 4). Despite the fact that the internet was mentioned as the most popular source of information, only $25.4 \%$ of the participants also trusted this source. Much more trust is advocated to pharmacists (68.1\%), physicians (58.1\%), and as third frequent family members $(28.5 \%)$. All results related to the sources of information are shown in Table 4.

In Table 5 we show results regarding participants' selfperceived knowledge about different topics concerning HM usage and their agreement whether or not they wish to be better informed. $35.3 \%$ of participants rated their knowledge about potential side effects as poor or very poor, compared to only $14.8 \%$ who thought to have good or very good knowledge about this topic. The situation is even more pronounced for potential interaction effects: $45.2 \%$ of the participants in group 1, i.e., almost half of the regular HM users, rated their knowledge on potential interaction effects as poor or very poor, and only $14.8 \%$ as good or very good. Moreover, it was found that in all topics essentially every other participant indicated that he/she wished he/she were better informed, and only $9.7 \%$ of the participants responded that they were informed well enough.

\section{Factors influencing HM usage}

Within this section, we analyse which factors can influence HM usage, i.e., we report the results from binary hierarchic logistic regression analysis, applying two different models as explained in the methods section.

Regarding the overall model evaluation, both logistic models showed statistical significance of $p=0.000$ in all likelihood-ratio tests, yielding the conclusion of model 
Table 3 Frequency table on indications for using $\mathrm{HM}$ and perceived helpfulness

\begin{tabular}{|c|c|c|c|c|c|}
\hline \multirow[t]{2}{*}{ INDICATIONS } & \multirow[t]{2}{*}{$\mathrm{N}$} & \multirow[t]{2}{*}{$\%$} & \multicolumn{3}{|c|}{ PERCEIVED HELPFULNESS (\%) } \\
\hline & & & Not at all & Somewhat & A great deal \\
\hline Common cold/flu infection & 1441 & 65.8 & 2.3 & 56.8 & 40.9 \\
\hline Respiratory problems & 1355 & 61.8 & 2.4 & 49.4 & 48.2 \\
\hline Gastrointestinal diseases & 1048 & 47.8 & 2.0 & 44.8 & 53.2 \\
\hline Sleeping disturbances & 655 & 29.9 & 15.7 & 53.4 & 30.9 \\
\hline Anxiety/restlessness & 500 & 22.8 & 13.6 & 54.4 & 32.0 \\
\hline Insect bites/itching & 437 & 19.9 & 3.9 & 33.9 & 62.2 \\
\hline Headaches/migraines & 386 & 17.6 & 10.9 & 54.4 & 34.7 \\
\hline Musculoskeletal problems & 353 & 16.1 & 12.8 & 60.6 & 26.6 \\
\hline Back/neck pain & 348 & 15.9 & 12.4 & 58.9 & 28.7 \\
\hline Bruises/sprains & 342 & 15.6 & 5.8 & 46.2 & 48.0 \\
\hline Chronic pain & 334 & 15.2 & 10.2 & 62.0 & 27.8 \\
\hline Gynaecological/urological problems & 311 & 14.2 & 7.1 & 48.2 & 44.7 \\
\hline Dermatosis & 293 & 13.4 & 9.9 & 48.5 & 41.6 \\
\hline Allergies/hay fever & 218 & 9.9 & 17.0 & 48.6 & 34.4 \\
\hline Depression & 185 & 8.4 & 24.9 & 51.9 & 23.2 \\
\hline Blood pressure problems & 169 & 7.0 & 14.2 & 59.2 & 26.6 \\
\hline Cardiovascular diseases & 144 & 6.6 & 8.3 & 56.3 & 35.4 \\
\hline High cholesterol & 89 & 4.1 & 18.0 & 57.3 & 24.7 \\
\hline Mental function & 86 & 3.9 & 18.6 & 51.2 & 30.2 \\
\hline Tinnitus & 68 & 3.1 & 52.9 & 33.8 & 13.3 \\
\hline Asthma & 63 & 2.9 & 23.8 & 49.2 & 27.0 \\
\hline Diabetes & 54 & 2.5 & 22.2 & 61.1 & 16.7 \\
\hline Cancer & 33 & 1.5 & 24.2 & 45.5 & 30.3 \\
\hline
\end{tabular}

$N=2192$ (group of HM users in the last 12 months, see Table 1); multiple answers allowed

Table 4 Frequency table on sources of information and trust in the source

\begin{tabular}{|c|c|c|c|c|}
\hline \multicolumn{3}{|c|}{ SOURCE OF INFORMATION } & \multicolumn{2}{|c|}{ TRUST IN SOURCE } \\
\hline & $\mathrm{N}$ & $\%$ & $\mathrm{~N}$ & $\%$ \\
\hline Internet & 1495 & 68.2 & 556 & 25.4 \\
\hline Pharmacist & 1187 & 54.2 & 1492 & 68.1 \\
\hline Family members & 1000 & 45.6 & 624 & 28.5 \\
\hline Physician & 849 & 38.7 & 1274 & 58.1 \\
\hline Friends & 760 & 34.7 & 318 & 14.5 \\
\hline Package insert & 755 & 34.4 & 577 & 26.3 \\
\hline Books & 668 & 30.5 & 528 & 24.1 \\
\hline Product package & 655 & 29.9 & 353 & 16.1 \\
\hline Journals/magazines & 592 & 27.0 & 254 & 11.6 \\
\hline
\end{tabular}

$N=2192$ (group of HM users in the last 12 months, see Table 1); multiple answers allowed effectiveness compared to the respective null models. The Hosmer-Lemeshow-test for assessing the goodness of the model fit again showed reasonable results, as demonstrated by non-significance for both models in all hierarchical blocks (model 1: first block: $\chi^{2}(8)=$ 6.291, $p=.615$; second block: $\left.\chi^{2}(8)=5.397, p=.714\right)$; model 2: first block: $\chi^{2}(8)=8.785, p=.361$; second block: $\chi^{2}(8)=12.282, p=.139$; third block: $\chi^{2}(8)=$ 9.516, $p=.301)$. The overall correct classification rate was $85.1 \%$ for model 1 and $87 \%$ for model 2 . The model evaluation, the goodness-of-fit statistics and the validation of the predicted probabilities demonstrated that both models fitted the data for distinguishing between the groups [25, 27, 31].

In regard to model 1 , as shown in Table 6 it was found that HM usage in the last 12 months (group 1) compared to HM non-usage (group 3) was significantly and positively associated with the variables being female (as the strongest predictor), living in bigger households, being employed, being educated for 12 or more years, and having private health insurance. The sociodemographic variables explained $9.8 \%$ of variance of the dependent 
Table 5 Frequency table on self-perceived knowledge about HM

\begin{tabular}{lllll}
\hline KNOWLEDGE & very poor, poor & moderate & good, very good & $\begin{array}{c}\text { "Yes, I wish I were } \\
\text { better informed" }\end{array}$ \\
\hline Visual identification and differentiation of raw medicinal plants & N (\%) & N (\%) & N (\%) & $\%$ \\
Medicinal effect and areas of application of raw medicinal herbs & $704(32.1)$ & $997(45.5)$ & $491(22.3)$ & 41.0 \\
Medicinal effects and areas of application of processed HM products & $469(21.3)$ & $1058(48.3)$ & $665(30.3)$ & 51.9 \\
Potential unwanted side effects of raw or processed HM products & $774(35.3)$ & $945(43.1)$ & $473(21.6)$ & 53.0 \\
Potential unwanted interaction effects with other HM products & $992(45.2)$ & $876(40.0)$ & $324(14.8)$ & 56.2 \\
Safe dosage and safe use & $361(16.5)$ & $908(41.4)$ & $923(42.1)$ & 43.4 \\
\hline
\end{tabular}

Total $N=2192$ (group of regular HM users, see Table 1); Question: "I wish I were better informed" allows for multiple answers

variable. Entering the health-related variables in a second block could improve the total amount of explained variance up to $15.3 \%$, whereby having chronic diseases, engaging in physical activities more than 2 times per week, and going to annual dentist check-ups were found to be factors significantly and positively associated with HM usage. In model 2, the following sociodemographic variables were found to be significantly and positively associated with being a HM user in the last 12 months (group 1) compared to being a less recent HM user (group 2): being female, being younger, and living in bigger households. The sociodemographic variables explained a rather small part of the variance of only $3.8 \%$. Entering the health-related variables could improve the prediction, explaining $6.2 \%$ of the variance. Having a chronic disease and going to annual dentist check-ups were found to be factors that were associated with a more recent $\mathrm{HM}$ use. Interestingly, including the ratings on different statements concerning reasons for HM usage within a third block of variables could improve the Nagelkerke $\mathrm{R}^{2}$ from .062 to .172 in model 2, which means the model could explain $17.2 \%$ of variance instead of $6.2 \%$. To be specific, the more someone agreed to the following reasons, the more likely the person belonged to group 1, HM users in the last 12 months: "I take HM because chemically synthesised medicinal products have too strong side effects", "I take HM because I had positive experiences with HM products", "I take HM because they have had a positive impact on my health" and "I take HM because within my family we have always used HM".

\section{Discussion}

In our study, we undertook a nationwide online survey on the general population in Germany to examine the role of HM in the German health-care system and to address important questions about the prevalence of HM usage, the users' characteristics, usage pattern, and factors influencing the use.

Our first important finding concerns HM prevalence rates for the general population in Germany, which were found to be impressively high (75.4\% 12-month prevalence, $86.7 \%$ lifetime prevalence) compared to those reported for other countries (e.g. 39.2\% of the general population in Turkey [15], 63.5\% in Kuwait [11], 36.8\% in Australia [17] or 33.9\% in Malaysia [14]). This finding is in line with the general trend of increasing prevalence rates of HM use in Germany, which can be observed comparing the 12-month prevalence rate of $26.6 \%$, found by Härtel \& Volger in 2004 [32], and 70\% reported in 2010 [16]. All of these results underline the importance of $\mathrm{HM}$ in the German health-care system. Why HM prevalence rates in Germany are higher than in other countries, and why they are increasing is a question that may not have a simple answer. But one can assume that these observations are related to the cultural and social embedment, individual values and experiences guiding specific reasons for a high prevalence of HM usage. It could also be a consequence of specifics of the German health-care system (e.g. health insurance and social security policies) as well as advanced marketing activities. Future research is required to understand the frequent user decisions for $\mathrm{HM}$ as treatment method in the society.

Regarding the sociodemographic- and health-related variables, the German HM user was found to be more likely female, highly educated, living in bigger households, and more likely to be privately insured and employed. These results are mostly in line with previous, well-established findings on HM [12, 15, 29, 30, 33, 34], especially concerning the variables of gender and education. Analysing the health-related aspects, HM users more often suffered from a chronic disease than nonregular or non-users, and showed a lifestyle that was clearly more health-oriented: HM users engaged more in physical activity, were more often non-smokers, and performed preventive health behaviour (e.g. preventive medical check-ups). Again, these results are mostly in line with previous research, as similar group differences were found, for example, also in the context of physical activities [12], smoking behaviour [15], and suffering from a chronic disease [30]. Moreover, in our sample we 
Table 6 Results of the two binary hierarchical regression analyses to identify influencing factors of herbal medicine use

\begin{tabular}{|c|c|c|c|c|c|c|c|c|}
\hline \multirow[b]{2}{*}{ Independent Variable } & \multicolumn{4}{|c|}{$\begin{array}{l}\text { Model 1: HM user in previous year }(1 ; n=2192) \\
\text { vs. HM non-user }(0 ; n=386)\end{array}$} & \multicolumn{4}{|c|}{$\begin{array}{l}\text { Model } 2 \text { : HM user in previous year } \\
(1 ; n=2192) \text { vs. HM user not in prev. } \\
\text { Year }(0 ; n=328)\end{array}$} \\
\hline & $\bar{B}$ & Adj. OR & $95 \% \mathrm{Cl}$ & $R^{2}$ & $B$ & Adj. OR & $95 \% \mathrm{Cl}$ & $R^{2}$ \\
\hline Gender (Female) & $1.060^{* *}$ & 2.887 & $2.241-3.719$ & & $.537^{* *}$ & 1.711 & $1.307-2.239$ & \\
\hline Age 18-29 & .364 & 1.439 & $.933-2.219$ & & $.537^{*}$ & 1.710 & $1.085-2.696$ & \\
\hline $30-39$ & -.157 & .855 & $.562-1.299$ & & $.542^{*}$ & 1.720 & $1.053-2.810$ & \\
\hline $40-49$ & -.093 & .911 & $.623-1.334$ & & .094 & 1.098 & $.721-1.673$ & \\
\hline $50-59$ & -.285 & .752 & $.532-1.064$ & & .020 & 1.020 & $.691-1.506$ & \\
\hline Size of household 2 & $.291 *$ & 1.337 & $1.014-1.763$ & & $.435^{* *}$ & 1.544 & $1.136-2.099$ & \\
\hline 3 & $.752^{* *}$ & 2.121 & $1.439-3.125$ & & $.431^{*}$ & 1.539 & $1.023-2.317$ & \\
\hline$\geq 4$ & $.669 * *$ & 1.952 & $1.326-2.872$ & & $.484^{*}$ & 1.623 & $1.070-2.461$ & \\
\hline Occupation (Employed) & .278 & 1.320 & $.993-1.754$ & & .148 & 1.160 & $.850-1.582$ & \\
\hline Education ( $\geq 12$ years) & $.461^{* *}$ & 1.585 & $1.240-2.027$ & & .235 & 1.265 & $.967-1.653$ & \\
\hline Health insurance (Private) & $.463^{* *}$ & 1.589 & $1.164-2.171$ & .098 & .179 & 1.195 & $.868-1.647$ & .038 \\
\hline Self-perceived health status (fair, poor, very poor) & -.099 & .906 & $.683-1.201$ & & .238 & 1.269 & $.936-1.719$ & \\
\hline Chronic disease (Yes) & $.882^{* *}$ & 2.416 & $1.836-3.178$ & & $.450^{* *}$ & 1.568 & $1.176-2.090$ & \\
\hline Smoking status (Former, Never) & .088 & 1.092 & $.851-1.402$ & & .086 & 1.089 & $.827-1.435$ & \\
\hline Regular alcohol consumption (No) & -.229 & .795 & $.623-1.015$ & & -.151 & .860 & $.658-1.124$ & \\
\hline Physical activities ( $\geq 3 \mathrm{~d}$./week) & $.431 * *$ & 1.538 & $1.208-1.960$ & & .192 & 1.212 & $.934-1.572$ & \\
\hline Flu vaccination (Yes) & .083 & 1.087 & $.802-1.472$ & & .124 & 1.132 & $.823-1.557$ & \\
\hline Annual dentist check-ups (Yes) & $.356^{* *}$ & 1.427 & $1.096-1859$ & & $.350^{*}$ & 1.419 & $1.056-1.906$ & \\
\hline Preventive medical check-ups (Yes) & .161 & 1.175 & $.905-1.525$ & & .087 & 1.091 & $.824-1.444$ & \\
\hline Current tetanus vaccination (Yes) & .175 & 1.192 & $.913-1.555$ & .153 & -.038 & .963 & $.712-1.301$ & .062 \\
\hline $\begin{array}{l}\text { "I take HM because chemically synthesised medicinal products } \\
\text { have too many side effects." }\end{array}$ & & & & & -.131 & .877 & $.726-1.060$ & \\
\hline $\begin{array}{l}\text { "I take HM because chemically synthesised medicinal products } \\
\text { have too strong side effects." }\end{array}$ & & & & & $2.09^{*}$ & 1.232 & $1.024-1.484$ & \\
\hline $\begin{array}{l}\text { "I take HM because chemically synthesised medicinal products } \\
\text { did not show treatment success." }\end{array}$ & & & & & -.070 & .932 & $.794-1.095$ & \\
\hline $\begin{array}{l}\text { "I take HM because I was dissatisfied with the conventional } \\
\text { medical practitioner." }\end{array}$ & & & & & .020 & 1.020 & $.876-1.188$ & \\
\hline $\begin{array}{l}\text { "I take HM because in the past, I had positive experiences with } \\
\text { herbal medicinal products." }\end{array}$ & & & & & $.334^{* *}$ & 1.397 & $1.155-1.689$ & \\
\hline $\begin{array}{l}\text { "I take HM because they have had a positive impact on } \\
\text { my health." }\end{array}$ & & & & & $.417^{* *}$ & 1.517 & $1.248-1.844$ & \\
\hline $\begin{array}{l}\text { "I take HM because they are healthier than chemically } \\
\text { synthesised medicinal products." }\end{array}$ & & & & & -.019 & .982 & $.821-1.174$ & \\
\hline $\begin{array}{l}\text { "I take HM because they are more natural than chemically } \\
\text { synthesised medicinal products." }\end{array}$ & & & & & -.004 & .996 & $.822-1.206$ & \\
\hline $\begin{array}{l}\text { "I take HM because they have a higher tolerability than } \\
\text { chemically synthesised medicinal products." }\end{array}$ & & & & & .127 & 1.136 & $.933-1.383$ & \\
\hline $\begin{array}{l}\text { "I take HM because they have less side effects than chemically } \\
\text { synthesised medicinal products." }\end{array}$ & & & & & -.078 & .925 & $.752-1.139$ & \\
\hline $\begin{array}{l}\text { "I take HM because I trust HM more than chemically synthesised } \\
\text { medicinal products." }\end{array}$ & & & & & -.069 & .933 & $.790-1.103$ & \\
\hline "I take HM because within my family we have always used HM." & & & & & $.269 * *$ & 1.308 & $1.121-1.527$ & \\
\hline $\begin{array}{l}\text { "I take HM because I am very familiar with herbal medicinal } \\
\text { products since my childhood." }\end{array}$ & & & & & -.096 & .909 & $.788-1.047$ & .172 \\
\hline
\end{tabular}

Note. Reference categories: gender: male; age: $60+$, size of household: 1; occupation: non-employed; education: < 12 years; health insurance: public; self-perceived health status: very good, good; chronic disease: no; smoking status: yes; regular alcohol consumption: yes; physical activities (0-2 d./ week); flu vaccination: no; annual dentist check-ups: no; preventive medical check-ups: no; current tetanus vaccination: no. $B=$ regression coefficient $b$; Adj. $\mathrm{OR}=$ adjusted odds ratio. $\mathrm{Cl}=$ confidence intervals for odds ratio. ${ }^{*} p \leq 0.05 ;{ }^{* *} p \leq 0.01 ; \mathrm{R}^{2}=$ Nagelkerkes Pseudo $\mathrm{R}^{2}$. Bold data are significant 
could not find group differences regarding the selfperceived health status, which is in contrast to the findings of previous research [12, 29, 34].

In our study, in total $93 \%$ of regular HM users were found to take HM in self-medication, which again can be interpreted as another form of proactive healthoriented behaviour. Hence, for regular HM users, influencing and managing their own health seems to be an important issue. The high percentage of self-medication related to $\mathrm{HM}$ is a phenomenon that has been frequently discussed in literature, together with the fact that users do not inform their physician about their "self-prescription" [12, 15, 17, 31, 34-37]. Also in our study, we found that only $38 \%$ of respondents using $\mathrm{HM}$ in selfmedication informed their physician about it, which is quantitatively similar to previous studies in Italy [33], the US [12], and Turkey [15]. As discussed in the literature, patients may furthermore overestimate the positive aspects of $\mathrm{HM}$ and may not be aware of existing potential side and interaction effects [37-41]. For example, Nur [15] found a clear lack of risk awareness: only $18 \%$ of HM users knew about possible interaction effects with other drugs, and Meier \& Lappas found a bias towards using natural vs. synthetic drugs regardless of safety and efficacy [42]. Taking all these outcomes together with the findings that the internet and not medicinal experts were noted as the most important information source in our study, and that HM users are not well-informed about the safety pattern of HM, there are clear signals of potential harm of HM usage in Germany, that health-care service providers and medicinal professionals should be aware of. Therefore, medicinal practitioners and pharmacists should actively ask their patients about their use of HM and inform them about HM safety profiles and interaction effects. These issues may be important especially for elderly HM users, who often take a number of prescribed and non-prescribed drugs $[35,36,43,44]$.

Regarding results of the binary hierarchical regression analyses, we first of all note that the value of the total $\mathrm{R}^{2}$, and therefore the amount of variance of the dependent variable explained after entering the sociodemographic and health-related variables, were found to be low. It was $15.3 \%$ for model 1 and only $6.2 \%$ for model 2, despite the fact that the overall model evaluations and the goodness of fit tests showed satisfactory results. Unfortunately, most previous studies reporting data from such models did not provide results on $R^{2}$, and thus we could not find a detailed discussion on this apparent issue in the literature. But we have found one study that reported similarly low $\mathrm{R}^{2}$ values for predicting HM use for children and adolescents in Germany [28]. Nevertheless, it should be stressed that using model 1 we found significant values for the variables of gender, size of household, occupation, level of education, health insurance, chronic disease, physical activities, and annual dentist check-ups in predicting regular HM usage. This confirms to a large degree results of studies that were conducted in other countries $[9,15,20]$. The fact that having private insurance is a significant predictor in Germany is plausible as it covers financial costs associated with HM use that public insurances does not. Using model 2 we found significant predictive power for being a 12-month user rather than a less recent HM user for the variables gender, age, size of household, chronic disease, and annual dentist check-ups. The fact that user ratings on reasons for usage of HM could improve the $\mathrm{R}^{2}$ by more than $50 \%$ up to a value of $.172(17.2 \%$ explained variance) is a very interesting result. It shows that for the decision making process regarding the proximity in time of HM usage (last year: yes/no), the reasons or motives of people played a decisive role. This clearly points to important further factors influencing HM usage that go beyond mere "classical" user variables, and may include individual experiences, beliefs, values, cultural and social background, and personality traits of users, which indicates several highly interesting topics to be explored in further research in the future.

Finally, we address potential shortcomings of our study: as was discussed throughout this text, a clear terminology is critical when studying HM usage. In the questionnaire of this study, it was ensured that a clear definition of HM was used, such that there would not be a bias for the participants. Nevertheless, we cannot exclude the possibility that some participants have had medicinal products in mind that were not within our definition of HM when answering the questionnaire. Furthermore, our study sample is potentially biased because it was an online-sample. This study design could affect sociodemographic characteristics in our sample and may impact our results, e.g., our finding that researching the internet was the most frequent source of information of HM users. Participants have actively chosen to participate in the survey, therefore, even if we did not explicitly include "interest in HM" as a criterion for selection in our sample, there could still be a slight bias towards oversampling participants that show a general interest in HM. In principle, this could lead to an overestimation of the HM prevalence rates. Lastly, our questionnaire included a retrospective question whether or not people used HM in lifetime or in the last 12 months. This may of course result in inaccurate information and, as a consequence wrong classification in the three user groups.

\section{Conclusion}

HM use was found to be common and widespread in the general German population with high prevalence rates, which demonstrates that is plays a central role in 
the health-care system in Germany. Future research is needed to explore in detail the reasons for this steady increase and the high user rates: Indeed, the user of HM in the last 12 months, the HM user who did not take $\mathrm{HM}$ in the last 12 months, and the HM non-user were found to differ in terms of certain sociodemographic and health-related variables. But as our data and analyses showed, the prediction of HM usage in the previous year was found to be improved by inclusion of other variables that addressed the reasons for HM usage. Selfmedication, small knowledge of interaction and sideeffects of HM, and a lack of communication about the usage were found to be part of the HM usage pattern. Taken together, and in view of the high prevalence rates of HM, this bears harm for patients of which healthservice providers should be aware of.

\section{Supplementary information}

Supplementary information accompanies this paper at https://doi.org/10. 1186/s12913-019-4739-0.

Additional file 1. Questions asked in the online survey. Questions and items that were asked in the online survey and are relevant to this study.

\section{Abbrevations}

CAM: Complementary and alternative medicine; HM: Herbal medicine

\section{Acknowledgements}

We would like to thank all the participants of our online survey. We also thank the funding institutions for the financial support.

\section{Authors' contributions}

All the authors contributed to the development of the ideas and the design of the study. ANW performed the data analysis and wrote the manuscript, which was revised by AEK and KM. All authors read and approved the final manuscript.

\section{Funding}

The presented work is part of the 'Extraktionsverfahren bioaktiver Naturstoffe aus Hopfen' project and is funded by the Federal Ministry of Education and Research (BMBF). This work was supported by the Technische Universität München within the funding programme Open Access Publishing.

\section{Availability of data and materials}

The dataset is available from the corresponding author upon reasonable request.

\section{Ethics approval and consent to participate}

Approved by the Ethics Commission of the Faculty of Medicine, Technical University of Munich on 08th January 2018. Participants gave written consent before beginning the questionnaire, which was recorded as part of the online survey.

\section{Consent for publication}

Not applicable.

\section{Competing interests}

The authors declare that they have no competing interests.
Received: 13 August 2018 Accepted: 12 November 2019

Published online: 10 December 2019

\section{References}

1. Eisenberg DM, Davis RB, Ettner SL, Appel S, Wilkey S, Van Rompay M, et al Trends in alternative medicine use in the United States, 1990-1997: results of a follow-up National Survey. JAMA. 1998;280:1569.

2. Eardley S, Bishop FL, Prescott P, Cardini F, Brinkhaus B, Santos-Rey K, et al. A systematic literature review of complementary and alternative medicine prevalence in EU. Forschende Komplementärmedizin / Research in Complementary Medicine. 2012;19:18-28.

3. Gratus C, Damery S, Wilson S, Warmington S, Routledge P, Grieve R, et al. The use of herbal medicines by people with cancer in the UK: a systematic review of the literature. QJM. 2009;102:831-42.

4. Fisher P. Ward A. Complementary medicine in Europe. BMJ. 1994;309:107-11.

5. Garcia-Alvarez A, Egan B, de Klein S, Dima L, Maggi FM, Isoniemi M, et al. Usage of plant food supplements across six European countries: findings from the PlantLIBRA consumer survey. PLoS One. 2014;9:e92265.

6. Arcury TA, Grzywacz JG, Bell RA, Neiberg RH, Lang W, Quandt SA. Herbal remedy use as health self-management among older adults. J Gerontol B Psychol Sci Soc Sci. 2007;62:S142-9.

7. Holst L, Wright D, Haavik S, Nordeng H. The use and the user of herbal remedies during pregnancy. J Altern Complement Med. 2009;15:787-92.

8. Gratus C, Wilson S, Greenfield SM, Damery SL, Warmington SA, Grieve R, et al. The use of herbal medicines by people with cancer: a qualitative study. BMC Complement Altern Med. 2009;9. https://doi.org/10.1186/14726882-9-14.

9. Peltzer K, Nguyen Huu T, Bach Ngoc N, Pengpid S. The use of herbal remedies and supplementary products among chronic disease patients in Vietnam. Studies on Ethno-Medicine. 2017:11:137-45.

10. Yeong SW, Choong YC. Knowledge and characteristics of herbal supplement usage among community pharmacy customers in a Malaysian population. Complement Ther Med. 2017;35:92-108.

11. Awad A, Al-Shaye D. Public awareness, patterns of use and attitudes toward natural health products in Kuwait: a cross-sectional survey. BMC Complement Altern Med. 2014;14. https://doi.org/10.1186/1472-6882-14-105.

12. Kennedy J. Herb and supplement use in the US adult population. Clin Ther. 2005;27:1847-58.

13. Gunther S, Patterson RE, Kristal AR, Stratton KL, White E. Demographic and health-related correlates of herbal and specialty supplement use. J Am Diet Assoc. 2004:104:27-34.

14. Aziz Z, Tey NP. Herbal medicines: prevalence and predictors of use among Malaysian adults. Complement Ther Med. 2009;17:44-50.

15. Nur N. Knowledge and behaviours related to herbal remedies: a crosssectional epidemiological study in adults in middle Anatolia, Turkey: use of herbal remedies. Health Soc Care Community. 2010;18:389-95.

16. Allensbach Institute for Opinion Research. Naturheilmittel. 2010. http://www ifd-allensbach.de.

17. Thomson P, Jones J, Evans JM, Leslie SL. Factors influencing the use of complementary and alternative medicine and whether patients inform their primary care physician. Complement Ther Med. 2012;20:45-53.

18. Bundesverband der Arzneimittel-Hersteller e.V. DER ARZNEIMITTELMARKT IN DEUTSCHLAND 2017 Zahlen und Fakten. https://www.bah-bonn.de/bah/ ?type=5658file=redakteur_filesystem/public/Bah_Zahlenbroschuer22017_ web.pdf.

19. Bundesverband der Arzneimittel-Hersteller e. DER ARZNEIMITTELMARKT IN DEUTSCHLAND 2015 Zahlen und Fakten. https://www.bah-bonn.de/bah/ ?type=565\&file=redakteur_filesystem/public/BAH-Zahlenbroschuere-2015web.pdf.

20. Wheaton AG, Blanck HM, Gizlice Z, Reyes M. Medicinal herb use in a population-based survey of adults: prevalence and frequency of use, reasons for use, and use among their children. Ann Epidemiol. 2005;15:678-85.

21. Zollman C, Vickers A. What is complementary medicine? BMJ. 1999:319:693-6.

22. Schendera CFG. Datenqualität mit SPSS. München: Oldenbourg; 2007.

23. https://nccih.nih.gov/research/statistics/NHIS. NHIS. https://nccih.nih.gov/ research/statistics/NHIS. Accessed 5 Mar 2018.

24. Welz AN, Emberger-Klein A, Menrad K. Why people use herbal medicine: insights from a focus-group study in Germany. BMC Complement Altern Med. 2018;18. https://doi.org/10.1186/s12906-018-2160-6.

25. Tabachnick BG, Fidell LS. Using multivariate statistics. 6. ed., internat. ed. Boston, Mass.: Pearson; 2013. 
26. Hilbe JM. Logistic regression models. Boca Raton: CRC Press; 2009.

27. Schendera CFG. Regressionsanalyse mit SPSS. 2. korrigierte und aktualisierte Auflage. München: De Gruyter Oldenbourg; 2014.

28. Du Y, Wolf I-K, Zhuang W, Bodemann S, Knöss W, Knopf H. Use of herbal medicinal products among children and adolescents in Germany. BMC Complement Altern Med. 2014;14:218.

29. Gardiner P, Graham R, Legedza ATR, Ahn AC, Eisenberg DM, Phillips RS. Factors associated with herbal therapy use by adults in the United States. Altern Ther Health Med. 2007;13:22-9.

30. Al-Windi A. Predictors of herbal medicine use in a Swedish health practice. Pharmacoepidemiol Drug Saf. 2004;13:489-96.

31. Peng C-YJ, Lee $\mathrm{KL}$, Ingersoll GM. An introduction to logistic regression analysis and reporting. J Educ Res. 2002;96:3-14.

32. Härtel U, Volger E. Inanspruchnahme und Akzeptanz klassischer Naturheilverfahren und alternativer Heilmethoden in Deutschland Ergebnisse einer repräsentativen Bevölkerungsstudie. Forschende Komplementärmedizin / Research in Complementary Medicine. 2004;11:327-34

33. Zaffani S, Cuzzolin L, Benoni G. Herbal products: behaviors and beliefs among Italian women. Pharmacoepidemiol Drug Saf. 2006;15:354-9.

34. Rashrash M, Schommer JC, Brown LM. Prevalence and predictors of herbal medicine use among adults in the United States. J Patient Exp. 2017:4:108-13

35. Bruno JJ, Ellis JJ. Herbal use among US elderly: 2002 National Health Interview Survey. Ann Pharmacother. 2005;39:643-8.

36. Samojlik I, Mijatović V, Gavarić N, Krstin S, Božin B. Consumers' attitude towards the use and safety of herbal medicines and herbal dietary supplements in Serbia. Int J Clin Pharm. 2013;35:835-40.

37. Calixto JB. Efficacy, safety, quality control, marketing and regulatory guidelines for herbal medicines (phytotherapeutic agents). Braz J Med Biol Res. 2000;33:179-89.

38. Zhang J, Onakpoya IJ, Posadzki P, Eddouks M. The safety of herbal medicine: from prejudice to evidence. Evid Based Complement Alternat Med. 2015;2015:1-3

39. Posadzki P. Watson LK, Ernst E. Adverse effects of herbal medicines: an overview of systematic reviews. Clin Med (Lond). 2013;13:7-12.

40. Izzo AA, Ernst E. Interactions between herbal medicines and prescribed drugs: a systematic review. Drugs. 2001;61:2163-75.

41. Abebe W. Herbal medication: potential for adverse interactions with analgesic drugs. J Clin Pharm Ther. 2002;27:391-401.

42. Meier BP, Lappas CM. The influence of safety, efficacy, and medical condition severity on natural versus synthetic drug preference. Med Decis Mak. 2016;36:1011-9.

43. de Souza Silva JE, Santos Souza CA, da Silva TB, Gomes IA, Brito G de C, de Souza Araújo AA, et al. Use of herbal medicines by elderly patients: a systematic review. Arch Gerontol Geriatr 2014;59:227-33.

44. González-Stuart A. Herbal product use by older adults. Maturitas. 2011;68:52-5.

\section{Publisher's Note}

Springer Nature remains neutral with regard to jurisdictional claims in published maps and institutional affiliations.

Ready to submit your research? Choose BMC and benefit from:

- fast, convenient online submission

- thorough peer review by experienced researchers in your field

- rapid publication on acceptance

- support for research data, including large and complex data types

- gold Open Access which fosters wider collaboration and increased citations

- maximum visibility for your research: over $100 \mathrm{M}$ website views per year

At $\mathrm{BMC}$, research is always in progress.

Learn more biomedcentral.com/submissions 